Indonesian Journal of Physics and Nuclear Applications

Volume 2, Number 3, October 2017, p. 137-143

e-ISSN 2550-0570, (C) FSM UKSW Publication

\title{
THE EFFECT OF THICKNESS VARIATION OF BERYLLIUM TARGET TOWARD CHARACTERISTICS OF NEUTRON ENERGY SPECTRUM ON CYCLOTRONS HM-30 USING MCNP-X
}

\author{
Sri Yuniarti*, Aris Haryadi, R. Farzand Abdullatif \\ Physics Department, Mathematics and Natural Science Faculty, Jenderal \\ Soedirman University, Purwokerto 53122, Indonesia \\ *E-mail address: syafis.unniiart@ gmail.com
}

\begin{abstract}
The research about the characterization of neutron energy spectrum as the effect of thickness variation of beryllium (Be) target on HM-30 cyclotron using Monte Carlo N-Particle eXtended (MCNP-X) has been conducted. This research aims to know the characteristics of neutron energy spectrum which are the result ofed by the reaction of $\operatorname{Be}(\mathrm{p}, \mathrm{n})$ with $\mathrm{HM}-30$ cyclotron as one of BNCT facilities. Modelling and simulation have been done by using MNCP-X software, then the data obtained is arranged on a graph by using Origin 8+. The result of the simulation shows that the characteristics of neutron energy spectrum of each thickness are in the range of fast neutron energy. The thicker the Beryllium target, the more diminishing the neutron energy will be.
\end{abstract}

Keywords Neutron Energy Spectrum, BNCT, Neutron, Beryllium, MCNP-X

\section{INTRODUCTION}

Cyclotrons are one type of ion accelerator-based neutron source (Mitsumoto, et al., 2013). The accelerator is widely used as a medical facility, one of Boron Neutron Capture Therapy (BNCT). BNCT was first described by Gordon J. Locher in 1936 (Zarma, et al., 2014). BNCT is an innovation in cancer therapy based on core capture reactions and fission reactions that occur when non-radioactive Boron-10 nuclides are irradiated with thermal neutrons for nuclear reactions $\left.{ }^{10} \mathrm{~B}(\mathrm{n}, \alpha)\right)^{7} \mathrm{Li}$ (Barth, et al., 2012; Sauerwein, et al., 2012). One type of cyclotron being developed as a BNCT application is HM-30 Cyclotrons. Cyclotron HM-30 accelerates negative hydrogen ions $\left(\mathrm{H}^{-}\right)$with a $1 \mathrm{~mA}$ current resulting in a $30 \mathrm{MeV}$ (Mitsumoto, et al., 2010). Cell targets for neutron production are an important part of the cyclotron. Beryllium (Be) is used as the target material on the cyclotron because it has the highest thermal conductivity, which is equal to $201 \mathrm{~W} / \mathrm{m} / \mathrm{K}$ compared to other target materials such as Lithium (Li), Wolfarm/Tungsten (W), and Tantalum (Ta) (Tanaka, et al., 2009).

The energy spectrum of neutron flux $\varphi(E)$ is a quantity that states the number of neutrons (per unit of energy) that have an energy range of about $\mathrm{E}$ and E+dE (Yazid, 2013). The characteristic of energy spectrum can provide information related to neutron energy (Spear, 2005; Harvey, 2010). Classification of energybased neutrons as in Table 2.1

Table 1. Type of Neutron Based on Energy Level (Yura and Fujita, 2013; Engenhart-Cabillic and Wambersie 1998)

\begin{tabular}{ll}
\hline Type of Neutron & Energy \\
\hline Fast Neutron & En $>10 \mathrm{keV}$ \\
Intermediate Neutron & $0,5 \mathrm{eV}<\mathrm{En}<10 \mathrm{keV}$ \\
(Epithermal Neutron) & \\
Thermal Neutron & En $<0,5 \mathrm{eV}$; at room \\
temperature $0,025 \mathrm{eV}$ \\
Cold Neutron & En $<0,025 \mathrm{eV}$ \\
\hline
\end{tabular}


The interaction of protons in Be has a random property that requires a method that can model the transport phenomenon, an effective method is Monte Carlo. Monte Carlo is packaged in a Monte Carlo N-Particle eXtended software (MCNP-X). MCNP-X can be used to calculate secondary particle flux densities, reaction rates of elastic/ inelastic scattering and other nuclear reactions, distribution of residual ions, deposited energy and energy distribution of pulses (Sedlačková, et al., 2013). Therefore, MCNP-X was used in this study to obtain neutron energy spectrum characteristics as the effect of Be target thickness variation.

\section{MATERIALS AND METHODS}

This research method is divided into three stages namely

\section{PREPARATION STAGE}

This stage consists of literature study and installation of $M C N P-X$ program, visedX22S.exe, Origin 8+

\section{STAGE GEOMETRY MODELLING}

At this stage the first is to model the source geometry simply in the form of a tubular beam transport with length $50 \mathrm{~mm}$ and diameter $120 \mathrm{~mm}$. After which it modelled the target geometry of a tube with a diameter of $190 \mathrm{~mm}$ and its thickness varied from 5.0 $\mathrm{mm}$ to $6.0 \mathrm{~mm}$. The entire listing is written with Notepad.

\section{STAGE OF CHARACTERIZATION OF NEUTRON ENERGY SPERCTRUM}

At this stage, the listing program is complete, then simulated and obtained the distribution of neutron energy for each thickness. Furthermore, the simulated results obtained are arranged into graphs using Origin $8+$, and the last one analyzes the energy spectrum of neutrons.

\section{RESULTS AND DISCUSSION}

\section{GEOMETRY MODELLING OF BERYLLIUM TARGET}

Modelling the system has been done as in the following figure, which consists of the beam transport, target cells, air space, and voids. Beam transport is modelled tube diameter 120 $\mathrm{mm}$ and length $50 \mathrm{~mm}$. The target cell portion of a cylinder having a diameter of $190 \mathrm{~mm}$ and its thickness varied from $5.0 \mathrm{~mm}$ to $6.0 \mathrm{~mm}$. In addition to beam transport and target cells, the system also consists of air space and voids. The air space serves as a boundary space for the system with the outside environment of the system. While the void is a space where MCNP-X does not simulate any interaction of particles. System geometry modelling in MCNP-X is presented in Figure 1.

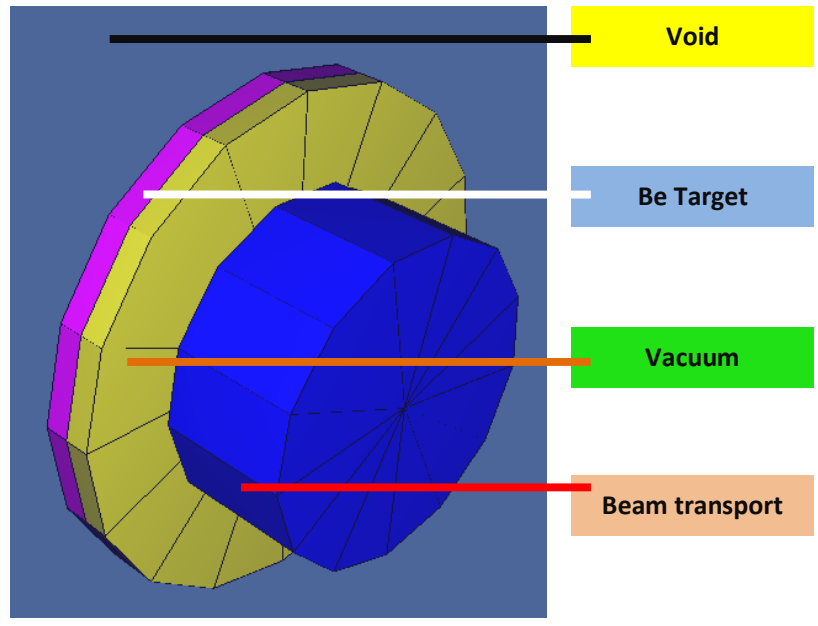

Fig.1 Modelling of system geometry withH MCNP-X

Protons as source particles are fired with 30 $\mathrm{MeV}$ of energy, operating current of $1.1 \mathrm{~mA}$, and fired radials from the tip of the $120 \mathrm{~mm}$ diameter beam transport. The scheme of firing is as shown in Figure 2. The total number of simulated particle history of 500.000.000 
particles. The tally used is $\mathrm{f} 4$, which gives the output in the form of counters in each bin of energy.

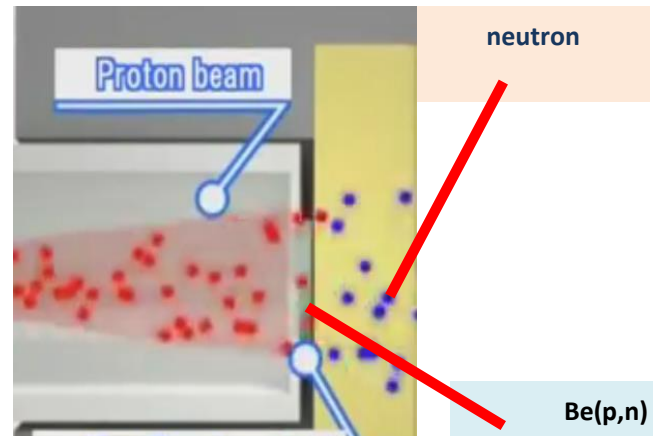

Benyllium tararget?

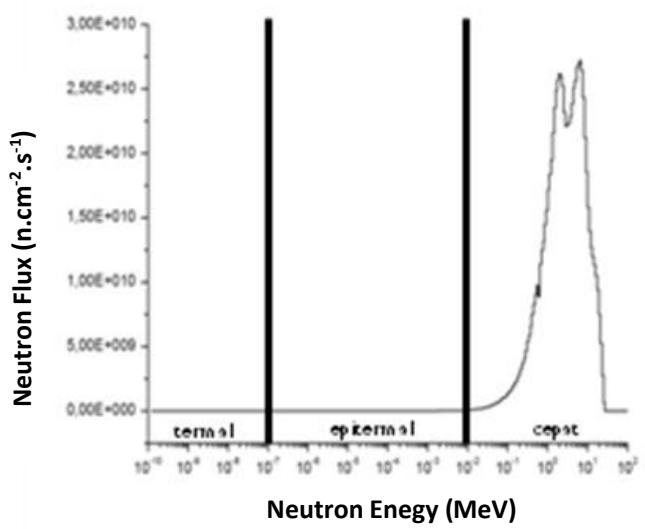

Fig.3 The neutron energy spectrum with a target thickness of $5.0 \mathrm{~mm}$ beryllium.

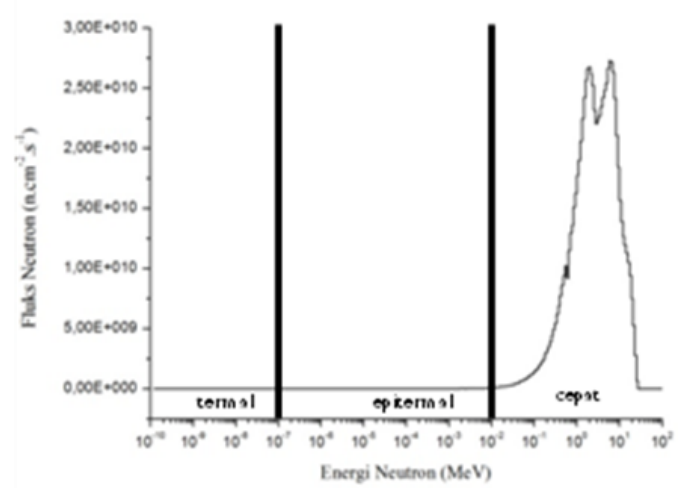

Fig.4 The neutron energy spectrum with a target thickness of $5.1 \mathrm{~mm}$ beryllium.

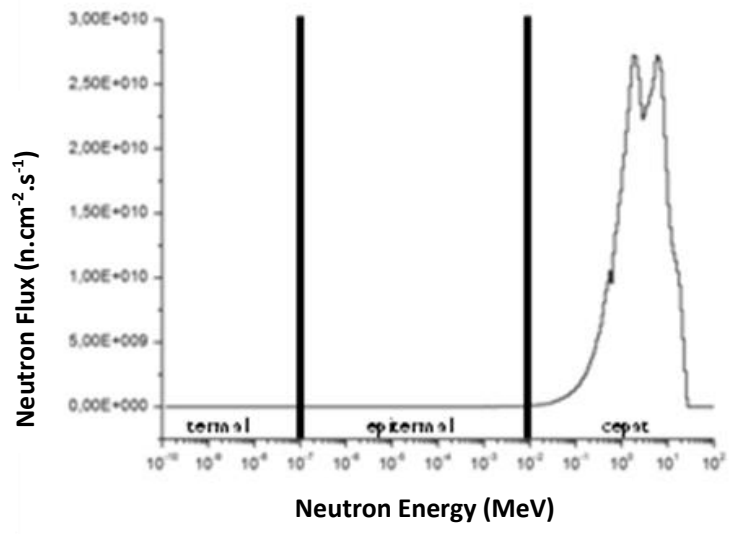

Fig.5 The neutron energy spectrum with a target thickness of $5.2 \mathrm{~mm}$ beryllium. 


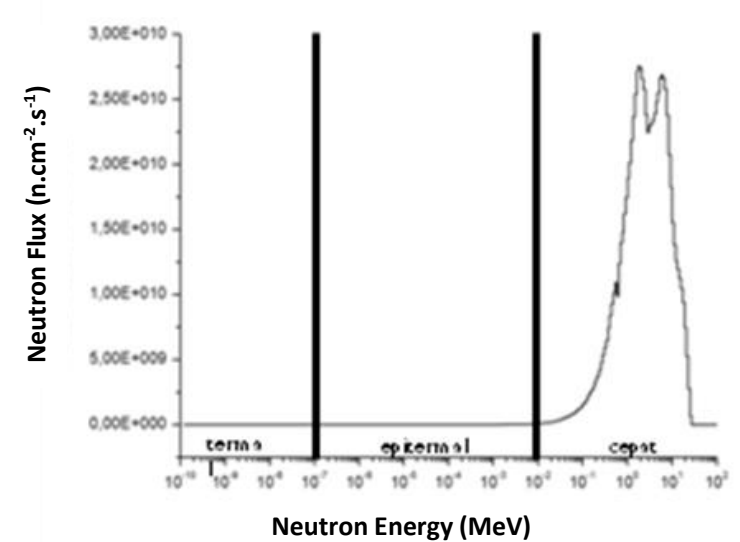

Fig.6 The neutron energy spectrum with a target thickness of $5.3 \mathrm{~mm}$ beryllium.

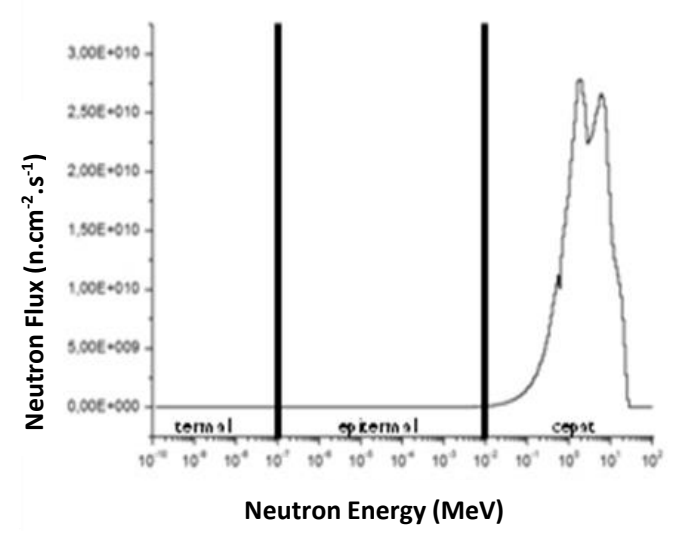

Fig.7 The neutron energy spectrum with a target thickness of $5.4 \mathrm{~mm}$ beryllium.

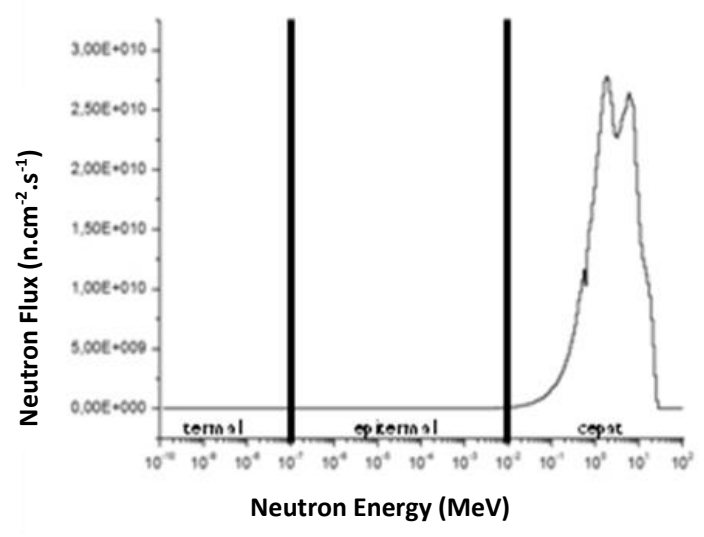

Fig. 8 The neutron energy spectrum with a target thickness of $5.5 \mathrm{~mm}$ beryllium

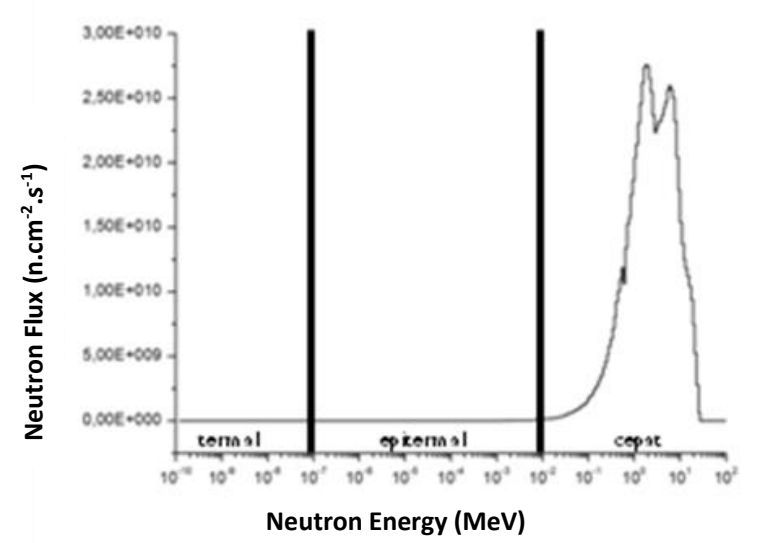

Fig.9 The neutron energy spectrum with a target thickness of $5.6 \mathrm{~mm}$ beryllium.

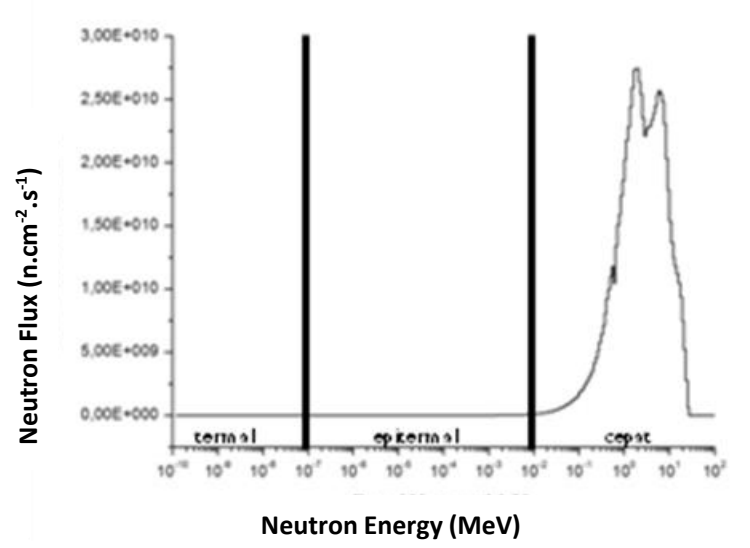

Fig.10 The neutron energy spectrum with a target thickness of $5.7 \mathrm{~mm}$ beryllium.

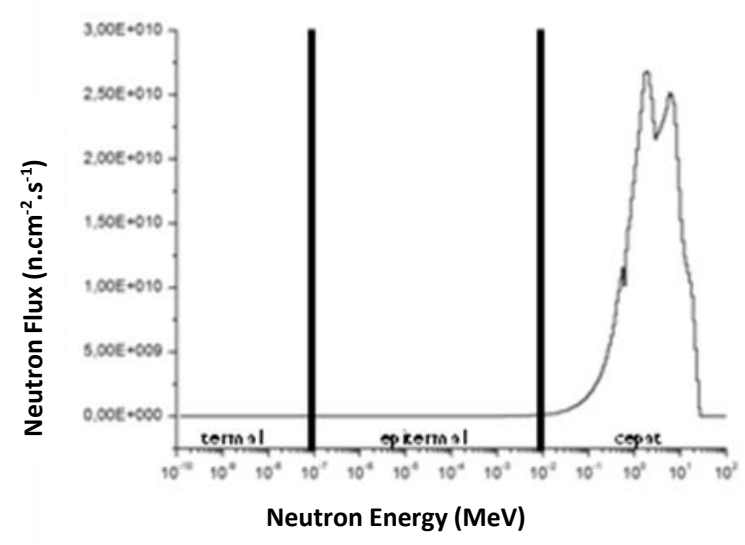


Fig.11 The neutron energy spectrum with a target thickness of $5.8 \mathrm{~mm}$ beryllium.

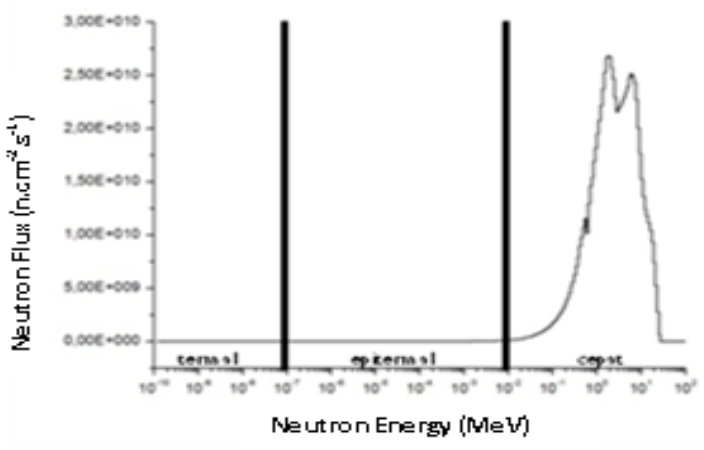

Fig.1 The neutron energy spectrum with a target thickness of $5.9 \mathrm{~mm}$ beryllium.

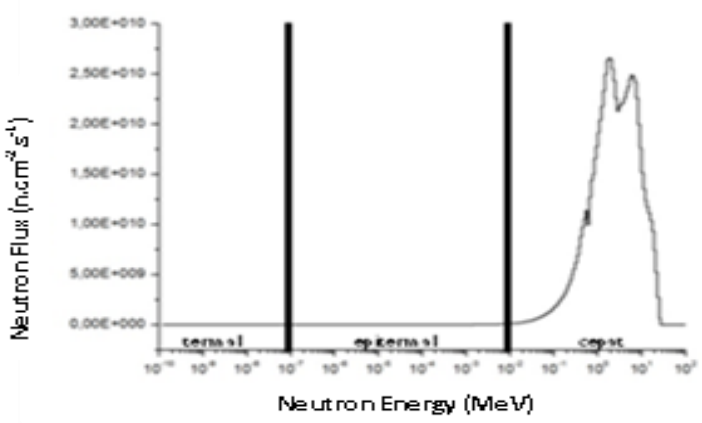

Fig.13 The neutron energy spectrum with a target thickness of $6.0 \mathrm{~mm}$ beryllium.

As shown in Figure 3 to Figure 13, it can be seen that the change in the shape of the neutron energy spectrum is not significant. The apparent change in the thickness of $5.2 \mathrm{~mm}$ is that two peaks appear the same. At a thickness of $5.0 \mathrm{~mm}$ and $5.1 \mathrm{~mm}$ having the same tendency of peaks that are on a larger neutron energy they have a higher neutron flux count than the peak at a smaller neutron energy. While at a thickness of $5.3 \mathrm{~mm}$ to $6.0 \mathrm{~mm}$, the peak that is at greater neutron energy has a lower number of neutron fluxes than the peak at smaller neutron energy. Thus, the thicker the target of beryllium, the resulting neutron flux dominance moves to smaller neutron energies. So the longer the reaction, the neutron energy will go down. The decrease can be seen in Table 2

Table 2. The peak change of the neutron energy spectrum.

\begin{tabular}{|c|c|c|c|c|}
\hline \multirow[b]{2}{*}{$\begin{array}{c}\text { Target Be } \\
\text { Thickness (mm) }\end{array}$} & \multicolumn{2}{|c|}{ Spectrum Peak Right } & \multicolumn{2}{|c|}{ Spectrum Peak Left } \\
\hline & $\begin{array}{c}\text { Neutron Flux } \\
\left(\text { n. } \mathrm{cm}^{-2} \cdot \mathrm{s}^{-1}\right)\end{array}$ & $\begin{array}{c}\text { Neutron } \\
\text { Energy }(\mathrm{MeV})\end{array}$ & $\begin{array}{l}\text { Neutron Flux } \\
\left(\text { n. } \mathrm{cm}^{-2} \cdot \mathrm{s}^{-1}\right)\end{array}$ & Neutron Energy (MeV) \\
\hline 5,0 & $2,72062 \times 10^{10}$ & 6,9800 & $2,61884 \times 10^{10}$ & 2,1163 \\
\hline 5,1 & $2,72873 \times 10^{10}$ & 6,3678 & $2,67196 \times 10^{10}$ & 2,1163 \\
\hline 5,2 & $2,72491 \times 10^{10}$ & 6,3678 & $2,72308 \times 10^{10}$ & 1,9307 \\
\hline 5,3 & $2,68841 \times 10^{10}$ & 6,3678 & $2,75603 \times 10^{10}$ & 1,9307 \\
\hline 5,4 & $2,66192 \times 10^{10}$ & 6,3678 & $2,78423 \times 10^{10}$ & 1,9307 \\
\hline 5,5 & $2,64023 \times 10^{10}$ & 6,3678 & $2,77963 \times 10^{10}$ & 1,9307 \\
\hline 5,6 & $2,59647 \times 10^{10}$ & 6,3678 & $2,76061 \times 10^{10}$ & 1,9307 \\
\hline 5,7 & $2,57266 \times 10^{10}$ & 6,3678 & $2,74281 \times 10^{10}$ & 1,9307 \\
\hline 5,8 & $2,53806 \times 10^{10}$ & 6,3678 & $2,71556 \times 10^{10}$ & 1,9307 \\
\hline 5,9 & $2,51471 \times 10^{10}$ & 6,3678 & $2,68188 \times 10^{10}$ & 1,9307 \\
\hline 6,0 & $2,48843 \times 10^{10}$ & 6,3678 & $2,65900 \times 10^{10}$ & 1,9307 \\
\hline
\end{tabular}


The peak in the energy spectrum is a neutron energy that has a higher flux than other energies. That is because the neutron of the proton reaction with $\mathrm{Be}$ reacts back to the Beryllium core through the reaction of ${ }^{9} \operatorname{Be}(n, 2 n+\alpha){ }^{4} \mathrm{He}$. Thus the number of neutrons in a given energy increases or the resulting flux value is higher than that of other neutron energies.

In the spectrum, neutron energy also has a slightly lower neutron flux. That's because the number of Helium as the end result of the reaction between neutrons with Be more than

the neutrons produced. As stated by Kuntjoro (2010), that Be reaction with fast neutrons continuously generates significant helium gas.

\section{CONCLUSION}

The conclusions obtained from the research are

a. The energy spectrum of each thickness has a distributed characteristic in the fast neutron energy range;

b. The resulting neutron energy increases to a certain thickness, and at the subsequent thickness of the neutron energy generated decreased;

\section{REFERENCES}

Barth, R. F., Vicente, M. G., Harling, K. O., Ill, W. S., Binns, P. J., Wagner, F. M., Suzuki, M., Aihara, T., Kato, I., Kawabata, S., (2012). Current Status of Boron Neutron Capture Therapy of High Grade Gliomas and Recurrent Head and Neck Cancer. Radiation Oncology 2012 , 7 (146). BioMed Central Ltd.
Engenhart-Cabillic, R., and Wambersie, A. (1998). Fast Neutrons and High-LET Particles in Cancer Therapy. ISBN-13: 9783-643-78776-8, ISSN 0080-0015. Heidelberg: Springer.

Harvey, Z. R. (2010). Neutron Flux and Energy Characterization of a Plutonium-Beryllium Isotopic Neutron Source by Monte Carlo Simulation with Verification by Neutron Activation Analysis. Thesis. University of Nevada. Las Vegas: UNLV University Libraries.

Kuntjoro, S. (2010). Analisis Pengaruh Iradiasi Fluens Neutron Cepat Terhadap Berilium Reflektor Reaktor RSG-GAS. Jurnal Teknologi Reaktor Nuklir, Vol. 12, No. 2, pp. 116-126.

Mitsumoto, T., Fujita, K., Ogaswara, T., Tsutsui, H., Yajima, S., Maruhashi, A., et al. (2010). BNCT System Using $30 \mathrm{MeV}$ H- Cyclotron. Proceedings of CYCLOTRONS 2010 , Lanzhou, China. pp. 430-432.

Mitsumoto, T., Yajima, S., Tsutsui, H., Ogaswara, T., Fujita, K., Tanaka, H., Sakurai, Y., Maruhashi, A. (2013). Cyclotron-Based Neutron Source for BNCT. Japan

Sauerwein, W. A., Moss, R., Wittig, A., Nagakawa, Y. (2012). Neutron Capture Therapy Principles and Applications. London: Springer.

Sedlačková, K., Zat'ko, B., Šagátova, A., Pavlovič, M., Nečas, V., and Stacho, M. (2014). MCNPX Monte Carlo Simulations of Particle Transport in SiC semiconductor detectors of Fast Neutrons. 15th International Workshop on Radiation Imaging Detectors. 23-27 June 2013. France: IOP Publishing, Ltd. and Sissa Medialab srl. doi: 10.1088/17480221/9/05/C05016

Spear, J. S. (2005). Characterizing Neutron Energy Spectrum Using A "Forward Edge" Neutron Time-Of-Flight Spectrocopy Technique. Thesis. Air Force Institute of Technology, Department of The Air Force 
Air University. USA: Wright-Patterson Air Force Base.

Tanaka, H., Sakurai, Y., Suzuki, M., Masunaga, S., Kinashi, Y., Kashino, G., Liu, Y., Mitsumoto, S., Yajima, S., Tsutsui, H., Maruhashi, A., Ono, K. (2009). Characteristics Comparison Between a Cyclotron-based Neutron Source and KUR-HWNIF for Boron Neutron Capture Therapy. Nuclear Instruments and Method in Physics Research B , 267, pp. 1970-1977. Elsevier, doi:10.1016/j.nimb.2009.03.095

Yazid, P. I. (2013). Perhitungan Spektrum Energi Fluks Neutron Reaktor TRIGA 2000 Bandung. Jurnal Sains dan Teknologi Nuklir Indonesia Vol. IV, ISSN 1411-3481 hal. 33- 46. Pusat Penelitian dan Pengembangan Teknik Nuklir-BATAN

Yura, Y., and Fujita, Y. (2013). Boron Neutron Capture Therapy as a Novel Modality of Radiotherapy for Oral Cancer: Principle and Antitumor Effect. Oral Science International Vol. 10, pp. 914. Japan : Osaka University, Elsevier, http://dx.doi.org/10.1016/S13488643(12)00046-8

Zarma, S. F., Mirea, D. A., Busca, I., Poroschianu, M. N., Verga, N. (2014). Implementing BNCT Through the Use of an Electron Accelerator. Romanian Reports in Physics Vol. 66 No.1, pp. 182191. Romania: ICRSH 2013 